\title{
Transcriptional Networks Controlling Adipocyte Differentiation
}

\author{
R. SiersbæK AND S. MANDRUP \\ Department of Biochemistry and Molecular Biology, University of Southern Denmark, \\ 5230 Odense M, Denmark \\ Correspondence: s.mandrup@bmb.sdu.dk
}

\begin{abstract}
Adipocyte differentiation is regulated by a complex cascade of signals that drive the transcriptional reprogramming of the fibroblastic precursors. Genome-wide analyses of chromatin accessibility and binding of adipogenic transcription factors make it possible to generate "snapshots" of the transcription factor networks operating at specific time points during adipogenesis. Using such global "snapshots," we have demonstrated that dramatic remodeling of the chromatin template occurs within the first few hours following adipogenic stimulation and that many of the early transcription factors bind in a cooperative fashion to transcription factor hotspots. Such hotspots are likely to represent key chromatin nodes, where many adipogenic signaling pathways converge to drive the adipogenic transcriptional reprogramming.
\end{abstract}

\section{INTRODUCTION}

\section{Models of Adipocyte Differentiation}

Adipocytes develop from mesenchymal stem cells (MSCs) in adipose tissue and to a lesser extent in various other tissues. This process involves an initial commitment phase where the MSCs are committed to the adipocyte lineage, followed by a differentiation phase where the preadipocytes develop into mature fat-laden adipocytes. Although, relatively little is known about the signaling pathways controlling commitment, the differentiation of preadipocytes to adipocytes (adipogenesis) is one of the best studied differentiation processes. Results obtained by a large number of laboratories using gain- and loss-of-function approaches have identified multiple interconnected signaling pathways controlling this differentiation process (Hwang et al. 1997; Rosen and Spiegelman 2000; MacDougald and Mandrup 2002; Farmer 2006; Rosen and MacDougald 2006; Lefterova and Lazar 2009; Siersbæk et al. 2010). The majority of discoveries of important adipogenic signaling pathways have been based on investigations in cell lines derived from mouse embryonic fibroblasts (Hwang et al. 1997), in particular the 3T3-L1 cell line (Green and Kehinde 1975). Although all these cell lines require a pharmacological cocktail of inducers to initiate the differentiation process, subsequent in vivo experiments have convincingly validated the physiological importance of the majority of these signaling pathways (Valet et al. 2002; Rosen and MacDougald 2006). Thus, these in vitro differentiation models represent a valuable tool for the identification of novel signaling networks regulating adipogenesis.

\section{External Signals Inducing Adipogenesis}

The adipogenic conversion of most mouse and human preadipocyte cell lines, including the murine 3T3-L1 cell line, requires stimulation with a pharmacological cocktail (MDI; Hwang et al. 1997). This cocktail consists of the synthetic glucocorticoid dexamethasone, the cAMP elevating agent 1-methyl-3-isobutyl xanthine (MIX), and pharmacological doses of insulin, which activates both the insulin receptor (IR) and the insulin-like growth factor receptor (IGF-R; Green and Kehinde 1975; Student et al. 1980; Schmidt et al. 1990; Yeh et al. 1995). In addition, efficient differentiation of many primary fibroblastic precursors requires supplementation with high affinity agonists of the peroxisome proliferator activated receptor $\gamma$ (PPAR $\gamma$; Wabitsch et al. 2001; Hansen et al. 2002; Janderova et al. 2003; Petrovic et al. 2010). The supremacy of the 3T3-L1 cell culture model for the study of adipogenesis is due to the fact that these cells, unlike most other models, can be brought to undergo a rather synchroneous and complete differentiation, which does not require pharmacological activation of PPAR $\gamma$. Thus, when the MDI cocktail in combination with fetal calf serum is administered to confluent 3T3-L1 cells, the cells undergo mitotic clonal expansion followed by growth arrest and induction of the adipocyte phenotype (Tang et al. 2003b). Lipid droplets become apparent 3-4 d after exposure to the cocktail.

The components of the MDI cocktail were originally empirically derived, and we have only recently begun to understand the downstream effector cascades. Dexamethasone is a key component of the adipogenic cocktail and is believed to induce the gene program by activating 
the glucocorticoid receptor (GR; Yeh et al. 1995; Pantoja et al. 2008). Consistent with this, knockdown of GR interfered with MDI-induced differentiation of 3T3-L1 preadipocytes (Steger et al. 2010). However, the mineralocorticoid receptor (MR) can also bind dexamethasone, and this receptor may also mediate additional effects of glucocorticoids on adipocyte differentiation (Caprio et al. 2007, 2011).

MIX is a phosphodiesterase inhibitor and therefore leads to elevated levels of cAMP, which activate protein kinase A (PKA; Reusch et al. 2000), as well as members of the family of exchange proteins directly activated by cAMP (Epac; Petersen et al. 2008). The cAMP response element-binding protein (CREB) is known to be activated by PKA-mediated phosphorylation and was originally thought to be the main effector of the cAMP signal (Reusch et al. 2000). However, more recent data indicate that PKA is dispensable for the CREB phosphorylation by MDI, which appears to rely more on activation of extracellular signal-regulated kinase $1 / 2$ (ERK1/2), whereas PKA plays an important role in inhibition of Rho and Rho kinase activity (Petersen et al. 2008). Thus, it is likely that the signaling cascade elicited by cAMP is much more complex than first anticipated and that several other transcription factors are directly or indirectly targeted by PKA and Epac. Potential candidates are CCAAT/enhancer-binding protein $(\mathrm{C} / \mathrm{EBP} \beta$; Tang et al. 2005) and Krüppel-like factor 4 (KLF4; Birsoy et al. 2008).

Insulin is administered in pharmacological doses and thus also activates the IGF-R, through which it is believed to stimulate the early phase of adipogenesis (Smith et al. 1988; Boney et al. 1998). IGF-R activates the ERK 1/2 and the phosphoinositide 3-kinase (PI3K) pathways, both of which appear to be required for adipogenesis (Sale et al. 1995; Sakaue et al. 1998; Tang et al. 2005), although the role of ERK $1 / 2$ is controversial (Font de Mora et al. 1997). Downstream effects of insulin/IGF-1 signaling include activation of $\mathrm{C} / \mathrm{EBP} \beta$ (Tang et al. $2005)$, the sterol regulatory element-binding protein 1 (SREBP-1; Lay et al. 2002), and CREB (Petersen et al. 2008), as well as inhibition of forkhead box protein $\mathrm{O} 1$ (FOXO1; Fan et al. 2009; Gerin et al. 2009).

Finally, growth hormone $(\mathrm{GH})$ from the fetal calf serum has been shown to activate signal transducer and activator of transcription $5 \mathrm{a} / \mathrm{b}$ (Stat5a/b) through Janus kinase-2 (JAK-2) (Yarwood et al. 1999), as well as C/ EBP $\beta$ through activation of ERK 1/2 (Cui et al. 2011).

\section{Transcriptional Cascades Regulating Adipogenesis}

The transcriptional regulation of adipocyte differentiation is known to rely on an intricate interplay between multiple adipogenic transcription factors. Among these PPAR $\gamma$ stands out as a key regulator obligate for in vitro as well as in vivo development of adipocytes and the only factor that can induce an adipocyte-like phentope upon ectopic expression in non-adipogenic cell types (Tontonoz and Spiegelman 2008). However, the function of PPAR $\gamma$ is tightly linked to members of the C/EBP family, which have well-documented important functions at different time points during adipocyte differentiation. $\mathrm{C} / \mathrm{EBP} \beta$ and $-\delta$ are already expressed in preadipocytes but are rapidly further induced (Cao et al. 1991; Tang and Lane 1999; Salma et al. 2006; Grøntved et al. 2010) and posttranslationally activated (Tang et al. 2005 ) by the adipogenic cocktail. The expression of $\mathrm{C} /$ EBP $\beta$ is induced by CREB and GR, whereas C/EBP $\delta$ is induced by GR (Cao et al. 1991; Pantoja et al. 2008). In addition, the ERK $1 / 2$ pathway induces phosphorylation and activation of C/EBP $\beta$ (Tang et al. 2005). $\mathrm{C} / \mathrm{EBP} \beta$ and $-\delta$ are direct activators of the expression of PPAR $\gamma$ and $\mathrm{C} / \mathrm{EBP} \alpha(\mathrm{Hamm}$ et al. 2001; Salma et al. 2004, 2006), the two major late-acting adipogenic transcription factors. These two transcription factors have been shown to mutually induce the expression of each other and to cooperate in the activation of the adipogenic gene program (Wu et al. 1999; Farmer 2006).

Although PPAR $\gamma$ and members of the C/EBP family form the classical core transcriptional network of adipogenesis, multiple other transcription factors have been demonstrated to play an important role, either early in differentiation or at later stages. These factors are linked together in a causal and temporal network, which forms at least two separate waves of adipogenic transcription factors (Fig. 1). In addition to $\mathrm{C} / \mathrm{EBP} \beta$ and $-\delta$, the first wave consists of early activators such as GR (Steger et al. 2010), Stat5a/b (Floyd and Stephens 2003), CREB (Reusch et al. 2000), KLF4 (Birsoy et al. 2008), KLF5 (Oishi et al. 2005) and Krox20 (Chen et al. 2005). Factors of the early wave directly or indirectly impact on the expression of factors of the second wave. The transcription factors of this wave, in particular PPAR $\gamma$ and $\mathrm{C} / \mathrm{EBP} \alpha$, drive the final adipocyte differentiation and/or modulate adipocyte metabolism. Factors such as SREBP-1 (Kim and Spiegelman 1996) and KLF15 (Mori et al. 2005) have been shown to play a role in adipocyte differentiation. The liver $\mathrm{X}$ receptor (LXR) modulates lipogenesis (Ross et al. 2002) and regulates expression of SREBP-1 (Repa et al. 2000) and PPAR $\gamma$ (Juvet et al. 2003).

\section{GENOME-WIDE INVESTIGATIONS OF TRANSCRIPTIONAL NETWORKS REGULATING ADIPOGENESIS}

\section{Genome-Wide Technologies and Global Maps of Transcription Factor Networks}

The recent advances in deep sequencing combined with chromatin immunoprecipitation (ChIP-seq) have enabled extensive mapping of transcription factors as well as epigenetic marks at a genome-wide level. We and others have used ChIP-seq as well as other global apporoaches to generate genome-wide binding profiles of PPAR $\gamma$ and $\mathrm{C} / \mathrm{EBP} \alpha$ and other transcription factors and epigenetic marks during adipocyte differentiation of murine (Lefterova et al. 2008; Nielsen et al. 2008; Hamza et al. 2009; Wakabayashi et al. 2009; Mikkelsen et al. 2010; Steger et al. 2010; Yu et al. 2010; reviewed 


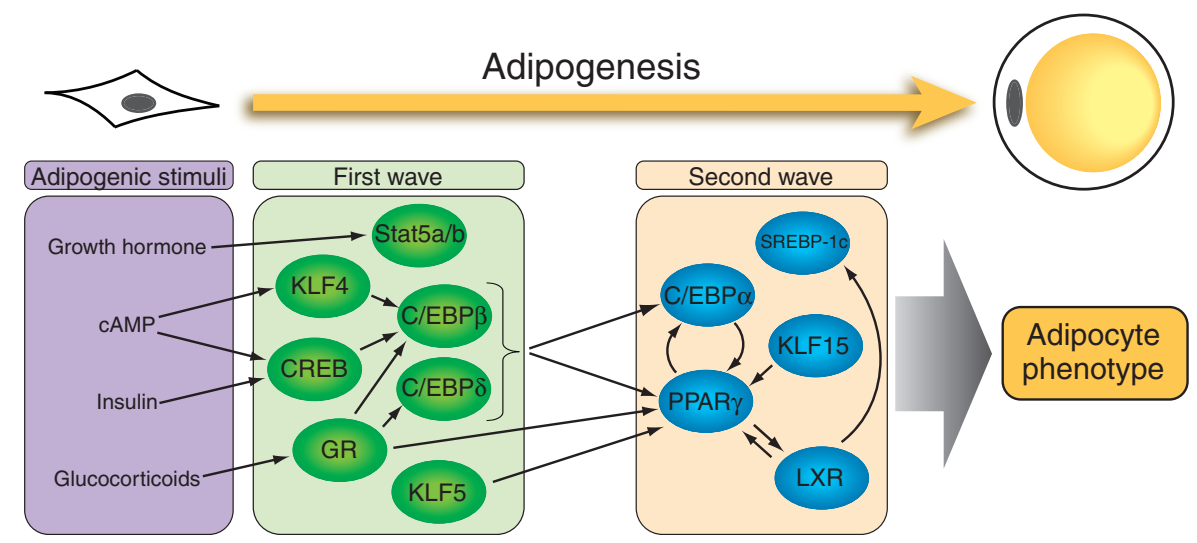

Figure 1. Outline of the transcriptional cascade controlling adipocyte differentiation. The adipogenic cocktail of inducers (i.e., insulin, glucocorticoids, a cAMP elevating agent, and serum containing high levels of growth hormone) activates the first wave of adipogenic transcription factors, which jointly induce the second wave of factors. The second wave, in which PPAR $\gamma$ and C/EBP $\alpha$ play a key role, directly induces and maintains the mature adipocyte phenotype. For simplicity, only a subset of transcription factors and interconnections are indicated.

in Siersbæk et al. 2010) and human adipocytes (Mikkelsen et al. 2010; Lo et al. 2011; Schmidt et al. 2011; Soccio et al. 2011). These genome-wide maps have greatly changed our view on transcriptional regulation of adipogenesis. First, the master regulator PPAR $\gamma$ is associated with the majority of genes that are induced during adipogenesis, indicating that PPAR $\gamma$ may be directly involved in the regulation of most genes linked to the adipocyte phenotype. Second, genes that are known to be regulated by PPAR $\gamma$ usually display multiple binding sites of PPAR $\gamma$ in the vicinity of the gene loci, and by far the majority of the identified binding sites are in intronic or intergenic regions. The same is the case for many other transcription factors. Thus, the sites most frequently investigated in reporter constructs, that is, sites near the proximal promoter, may only represent a fraction of the regulatory regime of a particular gene, and it may not even represent the most important regulatory site. Third, many transcription factors bind to the same regions as other transcription factors, indicating that there is significant cross talk between different transcription factors at the level of chromatin. This extensive sharing of binding sites/regions begs for investigations focusing on transcriptional networks in the sense of "snapshots" of global interconnections between transcription factors on chromatin. Such global "snapshots" focus on the functional interaction between transcription factors on chromatin at a given time, whereas the traditional temporal networks focus on when and how transcription factors are induced.

\section{Chromatin Remodeling during Adipogenesis}

The tight wrapping of DNA around histones to form nucleosomes restricts transcription factor access to target DNA elements embedded in chromatin. Thus, transcription factor binding directly to DNA is usually associated with remodeling of the chromatin structure to increase DNA accessibility. Because remodeling complexes are recruited to DNA by transcription factors,
DNA accessibility is both a cause and a consequence of transcription factor binding to DNA. Open remodeled regions can be detected by their hypersensitivity to attack by endonucleases such as DNase I and restriction enzymes. These DNase I hypersensitive (DHS) sites are likely to represent important "action points" in chromatin where transcription factors and other sequence specific proteins bind to DNA. Traditionally, individual DHS sites have been detected by Southern blotting (Wu et al. 1979; Wu 1980; Keene et al. 1981) and more recently by quantitative polymerase chain reaction (PCR; McArthur et al. 2001; Dorschner et al. 2004; Boyle et al. 2008; John et al. 2008). These techniques are well suited for quantification of chromatin accessibility at specific genomic regions; however, they are limited by their low throughput. To obtain a global view of the chromatin landscape in a given cell type, small DNA fragments released from limited DNase I digestions have recently been analyzed by microarray (DHS-chip; Crawford et al. 2006a; Sabo et al. 2006; Boyle et al. 2008) and deep sequencing (DHS-seq; Crawford et al. 2006b; Boyle et al. 2008; Hesselberth et al. 2009; Stitzel et al. 2010; John et al. 2011), resulting in the generation of genome-wide maps of cell type-specific putative regulatory elements.

We recently employed DHS-seq to generate genomewide maps of chromatin accessibility and thereby important "action points" in chromatin at various stages of 3T3-L1 adipocyte differentiation, that is, at $0 \mathrm{~h}, 2 \mathrm{~h}$, $4 \mathrm{~h}, 1 \mathrm{~d}, 2 \mathrm{~d}$, and $6 \mathrm{~d}$ following stimulation with the adipogenic cocktail (Siersbæk et al. 2011). So far only very few studies have investigated how the global pattern of chromatin accessibility changes in response to external stimuli (Biddie et al. 2011; Hurtado et al. 2011; John et al. 2011) or during development (Li et al. 2011; Thomas et al. 2011). Thus, our study of chromatin remodeling during adipogenesis represents one of the first studies to investigate changes in overall chromatin structure at a genome-wide level during a biological transition, and to our knowledge, the first to investigate this during a mammalian differentiation process. 


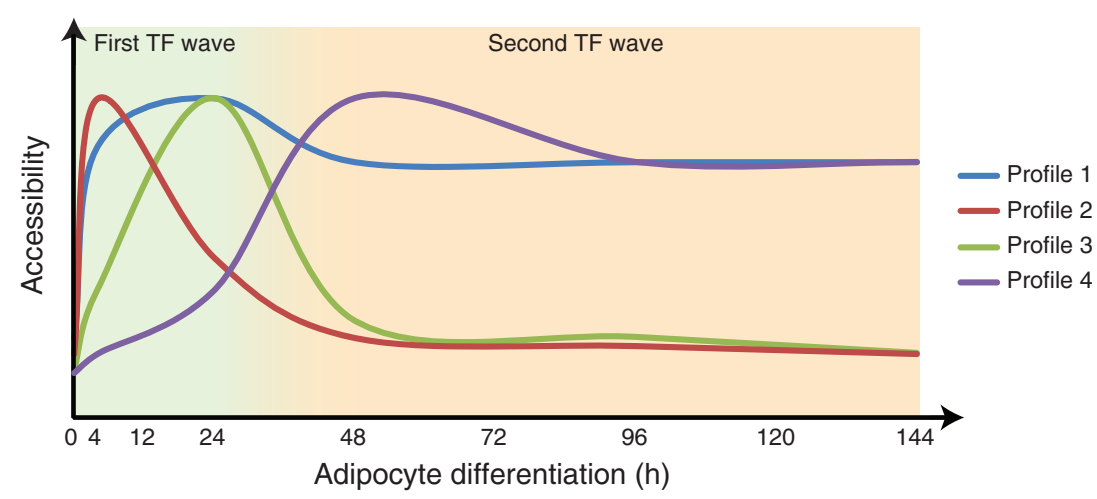

Figure 2. The four major modes of chromatin remodeling during 3T3-L1 adipocyte differentiation. Genomic regions that develop hypersensitivity to DNase I at some time point during 3T3-L1 adipogenesis were clustered based on their temporal profile of accessibility (i.e., sensitivity to DNase I). This resulted in four groups of genomic "action points" with distinct temporal profiles of accessibility (Siersbæk et al. 2011). TF, transcription factor.

We identified $\sim 35,000$ genomic regions that are DNase I hypersensitive at one or more of the investigated time points during adipogenesis (Siersbæk et al. 2011). Interestingly, by analyzing the development of DHS sites during differentiation, we detected a dramatic increase in the number of DHS sites already within $4 \mathrm{~h}$ after administration of the adipogenic hormone cocktail (Fig. 2). A subset of these early remodeled sites has a transiently open chromatin configuration that peaks at the $4 \mathrm{~h}$ time point (Fig. 2, profile 2), and these sites are enriched in the vicinity of early induced genes linked to translation, mitochondrion, and glucose catabolism. This suggests that these regulatory regions are involved in the initial reprogramming of transcription during differentiation. In contrast to these transiently open regions, a large proportion of the sites that are remodeled at $4 \mathrm{~h}$ maintain an open chromatin structure throughout the differentiation process (Fig. 2, profile 1). These early remodeled regions are enriched in the vicinity of both early and late induced genes, suggesting that they represent regulatory sites involved in transcriptional regulation of genes activated at both early and late stages of differentiation. This would imply that chromatin remodeling at some regulatory sites precedes transcriptional activation of late induced genes.

Another group of genomic regions peak in DNase I accessibility at day 1 of differentiation and display a closed chromatin configuration in mature adipocytes (Fig. 2, profile 3). These regions are enriched in the vicinity of genes that are transiently induced at day 1 , suggesting that adipogenic transcription factors transiently associate with many of these regions to drive expression of neighboring genes. The gene program that is transiently activated at this stage of differentiation consists of genes linked to DNA packaging, translation, and cell cycle, consistent with the fact that the cells go through mitotic clonal expansion at this early stage prior to terminal differentiation.

Coincident with the activation of the second wave of adipogenic transcription factors, a final group of genomic regions are remodeled around day 2 of differentiation and the open chromatin configuration at these sites persists throughout terminal differentiation (Fig. 2, profile 4). These late remodeled regions are highly enriched in the vicinity of genes induced late in adipogenesis, many of which are linked to lipid and glucose metabolism. This suggests that these regions are involved in the final adipogenic reprogramming of transcription that is important for acquisition of the mature adipocyte phenotype.

\section{Hotspots in the Early Wave of Adipogenic Factors}

Based on the dramatic remodeling of chromatin occurring within $4 \mathrm{~h}$ following addition of the adipogenic cocktail, we chose to focus our investigations on obtaining a "snapshot" of the transcriptional network established at the $4 \mathrm{~h}$ time point (Siersbæk et al. 2011). Using de novo motif search of the 6000 most prominent new DHS peaks at that time point, we identified enrichment of binding motifs for multiple factors of potential interest including GR, Stat5, and C/EBPs. ChIP-seq profiles of these factors as well as the retinoid $\mathrm{X}$ receptor, which we have previously documented to be binding to chromatin early in differentiation (Nielsen et al. 2008), demonstrated that binding of all factors is indeed enriched at DHS sites at $4 \mathrm{~h}$. This provides proof of principle that transcription factor binding sites can be predicted from de novo motif analyses of DHS profiles and emphasizes the combination of DHS-seq and bioinformatic analyses as a valuable discovery tool to identify potential novel regulators of biological processes in an unbiased manner.

Intriguingly, we found a high degree of overlap between the binding sites of all transcription factors investigated, with about 1000 transcription factor "hotspots" where all factors, that is, GR, Stat5a, C/EBP $\beta$, $\mathrm{C} / \mathrm{EBP} \delta$, and RXR, bind to the same site. These hotspots are found in remodeled regions, and DNase I accessibility appears to correlate positively with the number of associated transcription factors, with GR being the most deciding factor. Importantly, the hotspots are highly enriched in the vicinity of genes that are induced by the cocktail, whereas other sites with fewer factors associated are less enriched. Again, GR seems to be the most deciding 
factor. Thus, these data are consistent with the notion that open chromatin regions are associated with binding of transcription factors that recruit remodeling complexes. Furthermore, the data indicate that many hotspots represent functional enhancers that are already active at the $4 \mathrm{~h}$ time point. Most likely several other types of hotspots with different combinations of transcriptions factors exist (Fig. 3A). These early hotspots would represent key "action points" (i.e., major enhanceosomes) on chromatin where the early adipogenic signals converge through the activation and binding of different subsets of early adipogenic transcription factors to overlapping/ adjacent DNA elements.

\section{The Role of C/EBP $\beta$ in the Establishment of Hotspots}

The ChIP-seq profiles of transcription factors at the $4 \mathrm{~h}$ time point showed that, in particular, GR and RXR, but also Stat5a, overlap very significantly with $\mathrm{C} / \mathrm{EBP} \beta$ (RXR and GR 93\%; Stat5a 65\%) and to a lesser extent also with $-\delta$. This indicates that these two members of the $\mathrm{C} / \mathrm{EBP}$ family constitute common co-occupying factors for a number of early adipogenic transcription factors. ChIP-seq profiling showed that $\mathrm{C} / \mathrm{EBP} \beta$ binds to a large number of sites already prior to induction of differentiation, whereas binding of $\mathrm{C} / \mathrm{EBP} \delta$, GR, and Stat5a is considerably more dependent on the adipogenic cocktail. Hotspots could be divided in two different clusters - one where prominent $\mathrm{C} / \mathrm{EBP} \beta$ occupancy is already established prior to induction of differentiation, and another where $\mathrm{C} / \mathrm{EBP} \beta$ occupancy is significantly increased concomitantly with the binding of the other factors and remodeling of the sites. Interestingly, knockdown of C/ EBP $\beta$ resulted in significantly reduced recruitment of GR, Stat5a, and RXR to most of the hotspots investigated, even if C/EBPS occupancy was increased for many sites. This indicates that $\mathrm{C} / \mathrm{EBP} \beta$ may function as a pioneering factor for the establishment of at least a subset of hotspots. It remains to be investigated how $\mathrm{C} / \mathrm{EBP} \beta$ is pioneering the subsequent formation of early hotspots. However, recent data have shown that hotspots with $\mathrm{C} / \mathrm{EBP} \beta$ binding at time point 0 are highly enriched for active histone marks such as $\mathrm{H} 3 \mathrm{~K} 27 \mathrm{Ac}$ at this time point (R Siersbæk and S Mandrup, unpubl. data). The central role of $\mathrm{C} / \mathrm{EBP} \beta$ in establishment of early hotspots

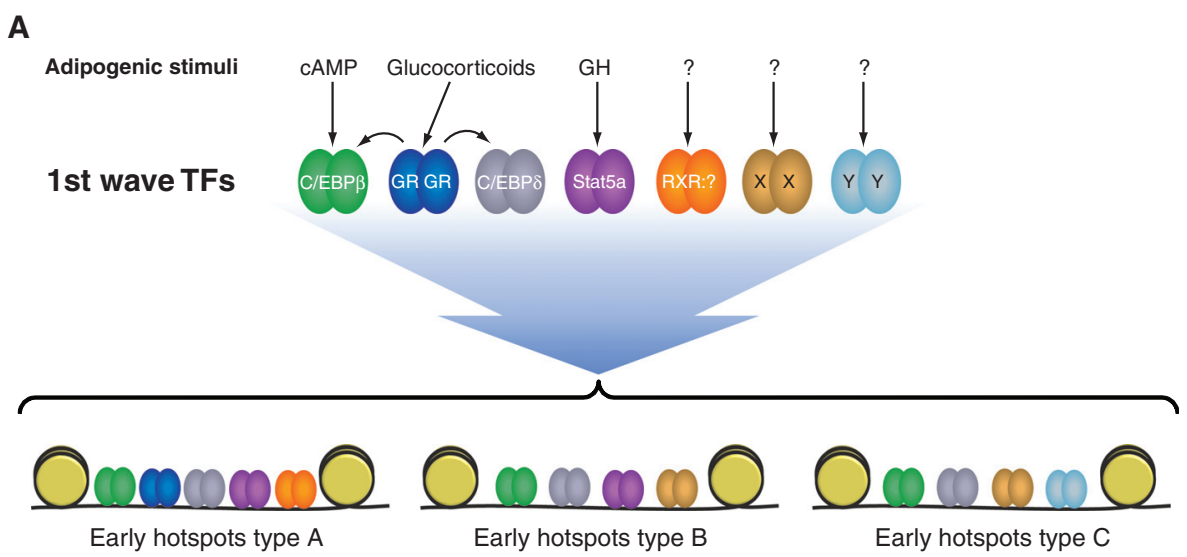

B

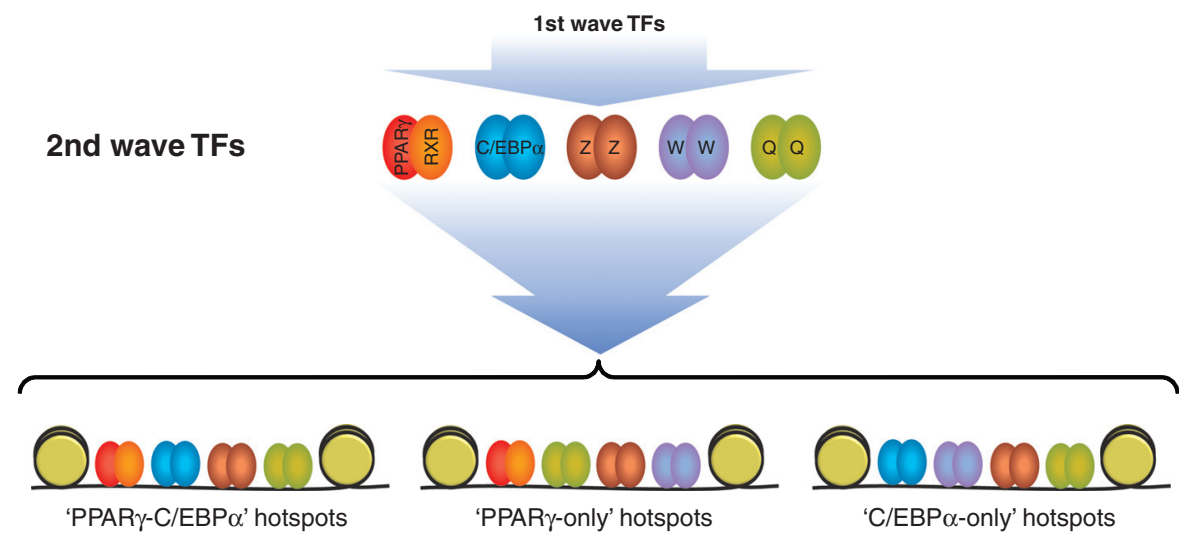

Figure 3. Adipogenic signals are integrated at transcription factor hotspots. $(A)$ Adipogenic inducers activate multiple early transcription factors, which in a cooperative fashion bind to a subset of accessible genomic regions (i.e., hotspots). Different types of hotspots occupied by distinct subsets of transcription factors seem to exist. $(B)$ The first wave of transcription factors induces late-acting adipogenic factors. Similar to the early factors, these late-acting transcription factors are likely to form different types of transcription factor hotspots integrating late adipogenic signals. GH, growth hormone. 
is consistent with its important role in adipocyte differentiation (Tanaka et al. 1997; Tang et al. 2003a).

\section{Cross Talk between PPAR $\gamma$ and C/EBP $\alpha$ in the Late Wave of Adipogenic Transcription Factors}

Based on our data demonstrating the existence of transcription factor hotspots in early stages of adipogenesis, we predict that different classes of hotspots are also present in the late adipogenic phase and in mature adipocytes (Fig. 3B). Similar to the early hotspots, these would integrate a number of adipogenic and metabolic signals on discrete genomic sites. Genome-wide ChIP-chip profiles from the Lazar laboratory demonstrated a high degree of overlap (63\%) between PPAR $\gamma$ and $\mathrm{C} / \mathrm{EBP} \alpha$ in 3T3-L1 cells (Lefterova et al. 2008). We subsequently documented a similar overlap using ChIP-seq analysis, and we showed that the overlap is conserved in human adipocytes (Schmidt et al. 2011).

Interestingly, comparison of mouse and human binding sites of PPAR $\gamma$ and $\mathrm{C} / \mathrm{EBP} \alpha$ at orthologous genomic positions demonstrates that the retention of mouse binding sites in human adipocytes is below $20 \%$ for PPAR $\gamma$ (Mikkelsen et al. 2010; Schmidt et al. 2011; Soccio et al. 2011) as well as $\mathrm{C} / \mathrm{EBP} \alpha$ (Schmidt et al. 2011). However, there are features that appear to increase the evolutionary pressure to maintain binding sites. These include binding strength (i.e., degree of occupancy) as well as vicinity to genes induced during differentiation. Intriguingly, overlap between $\mathrm{C} / \mathrm{EBP} \alpha$ and PPAR $\gamma$ binding also increases the frequency of retention, suggesting an increased functional importance of these sites and/ or cooperative mechanisms of binding (Schmidt et al. 2011). Furthermore, overall sequence conservation in the binding region also contributed greatly to retention of binding sites independent of conservation of the $\mathrm{C} /$ EBP and PPAR consensus binding sites. This is consistent with cooperative binding of additional transcription factors to these regions.

Cumulatively, these findings indicate a high degree of cooperativity between what has so far been established as the two main adipogenic transcription factors, PPAR $\gamma$ and $\mathrm{C} / \mathrm{EBP} \alpha$. In addition to stimulating the expression of each other (Farmer 2006), these two factors appear to cooperate in the activation of the adipogenic gene program by co-occupying a large fraction of the late adipogenic enhancers, most likely as part of an extensive network that involves multiple other late-acting adipogenic transcription factors. We propose that the activity and mode of action of a particular transcription factor like PPAR $\gamma$ may differ depending on the composition of the enhanceosome it is part of (Fig. 3B).

\section{Potential Cross Talk between Early and Late Hotspots}

As discussed above, the first wave of adipogenic transcription factors activates the next wave of factors including PPAR $\gamma$ and $\mathrm{C} / \mathrm{EBP} \alpha$. In addition, our analyses revealed that about one-third of all PPAR $\gamma$ binding sites are already remodeled $4 \mathrm{~h}$ following stimulation with the adipogenic cocktail, that is, long before PPAR $\gamma$ and $\mathrm{C} / \mathrm{EBP} \alpha$ are expressed. The majority of these early remodeled PPAR $\gamma$ binding sites are occupied by $\mathrm{C} / \mathrm{EBP} \beta$, suggesting that $\mathrm{C} / \mathrm{EBP} \beta$ could function as an early priming factor together with other factors that might occupy these sites. The functional importance of early versus late remodeling is currently unknown; however, it is intriguing that a large fraction of the early putative enhanceosomes appears to be "inherited" by late-acting enhanceosomes. This indicates that early enhanceosomes may prime the formation of late-acting enhanceosomes.

\section{CONCLUDING REMARKS}

Our findings presented above suggest that adipogenic signals converge at specific genomic hotspots, many of which are likely to represent important regulatory elements controlling reprogramming of transcription during adipocyte differentiation. Similarly, regions that are co-occupied by two or more transcription factors have been described in several other cell types, where they coordinate cell type-specific transcriptional programs (Chen et al. 2008; Heinz et al. 2010; Lefterova et al. 2010; Biddie et al. 2011; He et al. 2011). The precise molecular mechanisms governing establishment of such hotspots remain elusive, but several models can be envisioned (Aagaard et al. 2011): (1) Pioneering factors remodel the chromatin structure at hotspots to create an open chromatin configuration, which assists subsequent binding of additional transcription factors; (2) transcription factors bind to adjacent motifs and coordinate recruitment of co-factor complexes and the formation of an enhanceosome; (3) cooperating transcription factors alternate in binding to overlapping DNA elements and thus work in a sequential fashion to regulate transcription from hotspots; and (4) one or more of the transcription factors may associate with hotspots via an indirect mechanism involving protein-protein interactions. Such indirect recruitment of transcription factors may involve a classical tethering mechanism or interactions between factors bound at hotspots and factors bound at distal sites through looping of the intervening DNA. In addition to addressing how hotspots are established, it will be of key interest to discern the function of individual factors in the formation of enhanceosomes and in transcriptional regulation from such hotspots. Extensive molecular analyses in combination with gain- and loss-of-function experiments will be required to obtain an in-depth understanding of the cross talk between individual factors at transcription factor hotspots.

\section{ACKNOWLEDGMENTS}

The authors thank members of the Mandrup Laboratory for valuable discussions and input to the manuscript. This work was supported by funds from the Danish Natural Science Research Council and the Novo Nordisk Foundation. 


\section{REFERENCES}

Aagaard MM, Siersbæk R, Mandrup S. 2011. Molecular basis for gene-specific transactivation by nuclear receptors. Biochim Biophys Acta 1812: 824-835.

Biddie SC, John S, Sabo PJ, Thurman RE, Johnson TA, Schiltz RL, Miranda TB, Sung MH, Trump S, Lightman SL, et al. 2011. Transcription factor AP1 potentiates chromatin accessibility and glucocorticoid receptor binding. Mol Cell 43: $145-155$.

Birsoy K, Chen Z, Friedman J. 2008. Transcriptional regulation of adipogenesis by KLF4. Cell Metab 7: 339-347.

Boney CM, Smith RM, Gruppuso PA. 1998. Modulation of insulin-like growth factor I mitogenic signaling in 3T3-L1 preadipocyte differentiation. Endocrinology 139: $1638-$ 1644.

Boyle AP, Davis S, Shulha HP, Meltzer P, Margulies EH, Weng Z, Furey TS, Crawford GE. 2008. High-resolution mapping and characterization of open chromatin across the genome. Cell 132: 311-322.

Cao Z, Umek RM, McKnight SL. 1991. Regulated expression of three C/EBP isoforms during adipose conversion of 3T3-L1 cells. Genes Dev 5: 1538-1552.

Caprio M, Feve B, Claes A, Viengchareun S, Lombes M, Zennaro MC. 2007. Pivotal role of the mineralocorticoid receptor in corticosteroid-induced adipogenesis. FASEB $J$ 21: $2185-2194$.

Caprio M, Antelmi A, Chetrite G, Muscat A, Mammi C, Marzolla V, Fabbri A, Zennaro MC, Feve B. 2011. Antiadipogenic effects of the mineralocorticoid receptor antagonist drospirenone: Potential implications for the treatment of metabolic syndrome. Endocrinology 152: 113-125.

Chen Z, Torrens JI, Anand A, Spiegelman BM, Friedman JM. 2005. Krox20 stimulates adipogenesis via C/EBP $\beta$ dependent and -independent mechanisms. Cell Metab 1: 93-106.

Chen X, Xu H, Yuan P, Fang F, Huss M, Vega VB, Wong E, Orlov YL, Zhang W, Jiang J, et al. 2008. Integration of external signaling pathways with the core transcriptional network in embryonic stem cells. Cell 133: 1106-1117.

Crawford GE, Davis S, Scacheri PC, Renaud G, Halawi MJ, Erdos MR, Green R, Meltzer PS, Wolfsberg TG, Collins FS. 2006a. DNase-chip: A high-resolution method to identify DNase I hypersensitive sites using tiled microarrays. Nat Meth 3: $503-509$.

Crawford GE, Holt IE, Whittle J, Webb BD, Tai D, Davis S, Margulies EH, Chen Y, Bernat JA, Ginsburg D, et al. 2006b. Genome-wide mapping of DNase hypersensitive sites using massively parallel signature sequencing (MPSS). Genome Res 16: 123-131.

Cui TX, Lin G, LaPensee CR, Calinescu AA, Rathore M, Streeter C, Piwien-Pilipuk G, Lanning N, Jin H, Carter-Su C, et al. 2011. C/EBP $\beta$ mediates growth hormone-regulated expression of multiple target genes. Mol Endocrinol 25: 681-693.

Dorschner MO, Hawrylycz M, Humbert R, Wallace JC, Shafer A, Kawamoto J, Mack J, Hall R, Goldy J, Sabo PJ, et al. 2004. High-throughput localization of functional elements by quantitative chromatin profiling. Nat Meth 1: 219-225.

Fan W, Imamura T, Sonoda N, Sears DD, Patsouris D, Kim JJ, Olefsky JM. 2009. FOXO1 transrepresses peroxisome proliferator-activated receptor $\gamma$ transactivation, coordinating an insulin-induced feed-forward response in adipocytes. J Biol Chem 284: 12188-12197.

Farmer SR. 2006. Transcriptional control of adipocyte formation. Cell Metab 4: 263-273.

Floyd ZE, Stephens JM. 2003. STAT5A promotes adipogenesis in nonprecursor cells and associates with the glucocorticoid receptor during adipocyte differentiation. Diabetes 52: $308-314$.

Font de Mora J, Porras A, Ahn N, Santos E. 1997. Mitogenactivated protein kinase activation is not necessary for, but antagonizes, 3T3-L1 adipocytic differentiation. Mol Cell Biol 17: 6068-6075.
Gerin I, Bommer GT, Lidell ME, Cederberg A, Enerback S, MacDougald OA. 2009. On the role of FOX transcription factors in adipocyte differentiation and insulin-stimulated glucose uptake. J Biol Chem 284: 10755-10763.

Green H, Kehinde O. 1975. An established preadipose cell line and its differentiation in culture II. Factors affecting the adipose conversion. Cell 5: 19-27.

Grøntved L, Madsen MS, Boergesen M, Roeder RG, Mandrup S. 2010. MED14 tethers mediator to the N-terminal domain of peroxisome proliferator-activated receptor $\gamma$ and is required for full transcriptional activity and adipogenesis. Mol Cell Biol 30: 2155-2169.

Hamm JK, Park BH, Farmer SR. 2001. A role for C/EBP $\beta$ in regulating peroxisome proliferator-activated receptor $\gamma$ activity during adipogenesis in 3T3-L1 preadipocytes. J Biol Chem 276: $18464-18471$.

Hamza MS, Pott S, Vega VB, Thomsen JS, Kandhadayar GS, Ng PW, Chiu KP, Pettersson S, Wei CL, Ruan Y, Liu ET. 2009. De-novo identification of PPAR $\gamma /$ RXR binding sites and direct targets during adipogenesis. PLoS One 4: e4907.

Hansen JB, Petersen RK, Jorgensen C, Kristiansen K. 2002. Deregulated MAPK activity prevents adipocyte differentiation of fibroblasts lacking the retinoblastoma protein. $J$ Biol Chem 277: 26335-26339.

He A, Kong SW, Ma Q, Pu WT. 2011. Co-occupancy by multiple cardiac transcription factors identifies transcriptional enhancers active in heart. Proc Natl Acad Sci 108: $5632-5637$.

Heinz S, Benner C, Spann N, Bertolino E, Lin YC, Laslo P, Cheng JX, Murre C, Singh H, Glass CK. 2010. Simple combinations of lineage-determining transcription factors prime cis-regulatory elements required for macrophage and B cell identities. Mol Cell 38: 576-589.

Hesselberth JR, Chen X, Zhang Z, Sabo PJ, Sandstrom R, Reynolds AP, Thurman RE, Neph S, Kuehn MS, Noble WS, et al. 2009. Global mapping of protein-DNA interactions in vivo by digital genomic footprinting. Nat Meth 6: 283-289.

Hurtado A, Holmes KA, Ross-Innes CS, Schmidt D, Carroll JS. 2011. FOXA1 is a key determinant of estrogen receptor function and endocrine response. Nat Genet 43: 27-33.

Hwang CS, Loftus TM, Mandrup S, Lane MD. 1997. Adipocyte differentiation and leptin expression. Annu Rev Cell Dev Biol 13: $231-259$.

Janderova L, McNeil M, Murrell AN, Mynatt RL, Smith SR. 2003. Human mesenchymal stem cells as an in vitro model for human adipogenesis. Obes Res 11: 65-74.

John S, Sabo PJ, Johnson TA, Sung MH, Biddie SC, Lightman SL, Voss TC, Davis SR, Meltzer PS, Stamatoyannopoulo J, Hager GL. 2008. Interaction of the glucocorticoid receptor with the chromatin landscape. Mol Cell 29: 611-624.

John S, Sabo PJ, Thurman RE, Sung MH, Biddie SC, Johnson TA, Hager GL, Stamatoyannopoulo J. 2011. Chromatin accessibility pre-determines glucocorticoid receptor binding patterns. Nat Genet 43: 264-268.

Juvet LK, Andresen SM, Schuster GU, Dalen KT, Tobin KA, Hollung K, Haugen F, Jacinto S, Ulven SM, Bamberg K, et al. 2003. On the role of liver $\mathrm{X}$ receptors in lipid accumulation in adipocytes. Mol Endocrinol 17: 172-182.

Keene MA, Corces V, Lowenhaupt K, Elgin SC. 1981. DNase I hypersensitive sites in Drosophila chromatin occur at the $5^{\prime}$ ends of regions of transcription. Proc Natl Acad Sci 78: $143-146$.

Kim JB, Spiegelman BM. 1996. ADD1/SREBP1 promotes adipocyte differentiation and gene expression linked to fatty acid metabolism. Genes Dev 10: 1096-1107.

Lay SL, Lefrere I, Trautwein C, Dugail I, Krief S. 2002. Insulin and sterol-regulatory element-binding protein-1c (SREBP$1 \mathrm{C})$ regulation of gene expression in 3T3-L1 adipocytes. Identification of CCAAT/enhancer-binding protein $\beta$ as an SREBP-1C target. J Biol Chem 277: 35625-35634.

Lefterova MI, Lazar MA. 2009. New developments in adipogenesis. Trends Endocrinol Metab 20: 107-114. 
Lefterova MI, Zhang Y, Steger DJ, Schupp M, Schug J, Cristancho A, Feng D, Zhuo D, Stoeckert CJ Jr, Liu XS, Lazar MA. 2008. PPAR $\gamma$ and C/EBP factors orchestrate adipocyte biology via adjacent binding on a genome-wide scale. Genes Dev 22: 2941-2952.

Lefterova MI, Steger DJ, Zhuo D, Qatanani M, Mullican SE, Tuteja G, Manduchi E, Grant GR, Lazar MA. 2010. Cellspecific determinants of peroxisome proliferator-activated receptor $\gamma$ function in adipocytes and macrophages. Mol Cell Biol 30: 2078-2089.

Li XY, Thomas S, Sabo PJ, Eisen MB, Stamatoyannopoulo J, Biggin MD. 2011. The role of chromatin accessibility in directing the widespread, overlapping patterns of Drosophila transcription factor binding. Genome Biol 12: R34.

Lo KA, Bauchmann MK, Baumann AP, Donahue CJ, Thiede MA, Hayes LS, des Etages SA, Fraenkel E. 2011. Genomewide profiling of $\mathrm{H} 3 \mathrm{~K} 56$ acetylation and transcription factor binding sites in human adipocytes. PLoS One 6: e19778.

MacDougald OA, Mandrup S. 2002. Adipogenesis: Forces that tip the scales. Trends Endocrinol Metab 13: 5-11.

McArthur M, Gerum S, Stamatoyannopoulo G. 2001. Quantification of DNaseI-sensitivity by real-time PCR: Quantitative analysis of DNaseI-hypersensitivity of the mouse $\beta$-globin LCR. J Mol Biol 313: 27-34.

Mikkelsen TS, Xu Z, Zhang X, Wang L, Gimble JM, Lander ES, Rosen ED. 2010. Comparative epigenomic analysis of murine and human adipogenesis. Cell 143: 156-169.

Mori T, Sakaue H, Iguchi H, Gomi H, Okada Y, Takashima Y, Nakamura K, Nakamura T, Yamauchi T, Kubota N, et al. 2005. Role of Kruppel-like factor 15 (KLF15) in transcriptional regulation of adipogenesis. J Biol Chem 280: 12867-12875.

Nielsen R, Pedersen TA, Hagenbeek D, Moulos P, Siersbæk R, Megens E, Denissov S, Borgesen M, Francoijs KJ, Mandrup S, Stunnenberg HG. 2008. Genome-wide profiling of PPAR $\gamma:$ RXR and RNA polymerase II occupancy reveals temporal activation of distinct metabolic pathways and changes in RXR dimer composition during adipogenesis. Genes Dev 22: 2953-2967.

Oishi Y, Manabe I, Tobe K, Tsushima K, Shindo T, Fujiu K, Nishimura G, Maemura K, Yamauchi T, Kubota N, et al. 2005. Krüppel-like transcription factor KLF5 is a key regulator of adipocyte differentiation. Cell Metab 1: 27-39.

Pantoja C, Huff JT, Yamamoto KR. 2008. Glucocorticoid signaling defines a novel commitment state during adipogenesis in vitro. Mol Biol Cell 19: 4032-4041.

Petersen RK, Madsen L, Pedersen LM, Hallenborg P, Hagland H, Viste K, Doskeland SO, Kristiansen K. 2008. Cyclic AMP (cAMP)-mediated stimulation of adipocyte differentiation requires the synergistic action of Epac- and cAMPdependent protein kinase-dependent processes. Mol Cell Biol 28: 3804-3816.

Petrovic N, Walden TB, Shabalina IG, Timmons JA, Cannon B, Nedergaard J. 2010. Chronic peroxisome proliferator-activated receptor $\gamma$ (PPAR $\gamma$ ) activation of epididymally derived white adipocyte cultures reveals a population of thermogenically competent, UCP1-containing adipocytes molecularly distinct from classic brown adipocytes. $J$ Biol Chem 285: 7153-7164.

Repa JJ, Liang G, Ou J, Bashmakov Y, Lobaccaro JM, Shimomura I, Shan B, Brown MS, Goldstein JL, Mangelsdorf DJ. 2000. Regulation of mouse sterol regulatory element-binding protein-1c gene (SREBP-1c) by oxysterol receptors, LXR $\alpha$ and LXRß. Genes Dev 14: 2819-2830.

Reusch JEB, Colton LA, Klemm DJ. 2000. CREB activation induces adipogenesis in 3T3-L1 Cells. Mol Cell Biol 20: $1008-1020$.

Rosen ED, MacDougald OA. 2006. Adipocyte differentiation from the inside out. Nat Rev Mol Cell Biol 7: 885-896.

Rosen ED, Spiegelman BM. 2000. Molecular regulation of adipogenesis. Annu Rev Cell Dev Biol 16: 145-171.

Ross SE, Erickson RL, Gerin I, DeRose PM, Bajnok L, Longo KA, Misek DE, Kuick R, Hanash SM, Atkins KB, et al.
2002. Microarray analyses during adipogenesis: understanding the effects of WNT signaling on adipogenesis and the roles of liver $\mathrm{X}$ receptor $\alpha$ in adipocyte metabolism. Mol Cell Biol 22: 5989.

Sabo PJ, Kuehn MS, Thurman R, Johnson BE, Johnson EM, Cao H, Yu M, Rosenzweig E, Goldy J, Haydock A, et al. 2006. Genome-scale mapping of DNase I sensitivity in vivo using tiling DNA microarrays. Nat Meth 3: $511-518$.

Sakaue H, Ogawa W, Matsumoto M, Kuroda S, Takata M, Sugimoto T, Spiegelman BM, Kasuga M. 1998. Posttranscriptional control of adipocyte differentiation through activation of phosphoinositide 3-kinase. J Biol Chem 273: 2894528952.

Sale EM, Atkinson PG, Sale GJ. 1995. Requirement of MAP kinase for differentiation of fibroblasts to adipocytes, for insulin activation of p90 S6 kinase and for insulin or serum stimulation of DNA synthesis. EMBO J 14: 674-684.

Salma N, Xiao H, Mueller E, Imbalzano AN. 2004. Temporal recruitment of transcription factors and SWI/SNF chromatinremodeling enzymes during adipogenic induction of the peroxisome proliferator-activated receptor $\gamma$ nuclear hormone receptor. Mol Cell Biol 24: 4651-4663.

Salma N, Xiao H, Imbalzano AN. 2006. Temporal recruitment of CCAAT/enhancer-binding proteins to early and late adipogenic promoters in vivo. J Mol Endocrinol 36: 139-151.

Schmidt W, Poll JG, Loffler G. 1990. Adipose conversion of 3T3-L1 cells in a serum-free culture system depends on epidermal growth factor, insulin-like growth factor I, corticosterone, and cyclic AMP. J Biol Chem 265: 15489-15495.

Schmidt S, Jorgensen M, Chen Y, Nielsen R, Sandelin A, Mandrup S. 2011. Cross species comparison of C/EBP $\alpha$ and PPAR $\gamma$ profiles in mouse and human adipocytes reveals interdependent retention of binding sites. BMC Genomics 12: 152 .

Siersbæk R, Nielsen R, Mandrup S. 2010. PPAR $\gamma$ in adipocyte differentiation and metabolism-Novel insights from genome-wide studies. FEBS Lett 584: 3242-3249.

Siersbæk R, Nielsen R, John S, Sung MH, Baek S, Loft A, Hager GL, Mandrup S. 2011. Extensive chromatin remodelling and establishment of transcription factor "hotspots" during early adipogenesis. EMBO J 30: 1459-1472.

Smith PJ, Wise LS, Berkowitz R, Wan C, Rubin CS. 1988. Insulin-like growth factor-I is an essential regulator of the differentiation of 3T3-L1 adipocytes. J Biol Chem 263: 9402-9408.

Soccio RE, Tuteja G, Everett LJ, Li Z, Lazar MA, Kaestner KH. 2011. Species-specific strategies underlying conserved functions of metabolic transcription factors. Mol Endocrinol 25: 694-706.

Steger DJ, Grant GR, Schupp M, Tomaru T, Lefterova MI, Schug J, Manduchi E, Stoeckert CJ Jr, Lazar MA. 2010. Propagation of adipogenic signals through an epigenomic transition state. Genes Dev 24: 1035-1044.

Stitzel ML, Sethupathy P, Pearson DS, Chines PS, Song L, Erdos MR, Welch R, Parker SC, Boyle AP, Scott LJ, et al. 2010. Global epigenomic analysis of primary human pancreatic islets provides insights into type 2 diabetes susceptibility loci. Cell Metab 12: 443-455.

Student AK, Hsu RY, Lane MD. 1980. Induction of fatty acid synthetase synthesis in differentiating 3T3-L1 preadipocytes. J Biol Chem 255: 4745-4750.

Tanaka T, Yoshida N, Kishimoto T, Akira S. 1997. Defective adipocyte differentiation in mice lacking the C/EBP 3 and/ or C/EBP gene. EMBO J 16: 7432-7443.

Tang QQ, Lane MD. 1999. Activation and centromeric localization of CCAAT/enhancer-binding proteins during the mitotic clonal expansion of adipocyte differentiation. Genes Dev 13: 2231-2241.

Tang QQ, Otto TC, Lane MD. 2003a. CCAAT/enhancerbinding protein $\beta$ is required for mitotic clonal expansion during adipogenesis. Proc Natl Acad Sci 100: 850-855.

Tang QQ, Otto TC, Lane MD. 2003b. Mitotic clonal expansion: A synchronous process required for adipogenesis. Proc Natl Acad Sci 100: 44-49. 
Tang QQ, Gronborg M, Huang H, Kim JW, Otto TC, Pandey A, Lane MD. 2005. Sequential phosphorylation of CCAAT enhancer-binding protein $\beta$ by MAPK and glycogen synthase kinase $3 \beta$ is required for adipogenesis. Proc Natl Acad Sci 102: 9766-9771.

Thomas S, Li XY, Sabo PJ, Sandstrom RB, Thurman RE, Canfield TD, Giste E, Fisher W, Hammonds A, Celniker SE, et al. 2011. Dynamic reprogramming of chromatin accessibility during Drosophila embryo development. Genome Biol 12: R43.

Tontonoz P, Spiegelman BM. 2008. Fat and beyond: The diverse biology of PPAR $\gamma$. Annu Rev Biochem 77: 289-312.

Valet P, Tavernier G, Castan-Laurell I, Saulnier-Blache JS, Langin D. 2002. Understanding adipose tissue development from transgenic animal models. $J$ Lipid Res 43: 835-860.

Wabitsch M, Brenner RE, Melzner I, Braun M, Moller P, Heinze E, Debatin KM, Hauner H. 2001. Characterization of a human preadipocyte cell strain with high capacity for adipose differentiation. Int J Obes Relat Metab Disord 25: 8-15.

Wakabayashi Ki, Okamura M, Tsutsumi S, Nishikawa NS, Tanaka T, Sakakibara I, Kitakami Ji, Ihara S, Hashimoto Y, Hamakubo T, et al. 2009. The peroxisome proliferatoractivated receptor $\gamma /$ retinoid X receptor $\alpha$ heterodimer targets the histone modification enzyme PR-Set7/Setd8 gene and regulates adipogenesis through a positive feedback loop. Mol Cell Biol 29: 3544-3555.
Wu C. 1980. The $5^{\prime}$ ends of Drosophila heat shock genes in chromatin are hypersensitive to DNase I. Nature 286: 854-860.

Wu C, Wong YC, Elgin SC. 1979. The chromatin structure of specific genes: II. Disruption of chromatin structure during gene activity. Cell 16: 807-814.

Wu Z, Rosen ED, Brun R, Hauser S, Adelmant G, Troy AE, McKeon C, Darlington GJ, Spiegelman BM. 1999. Crossregulation of $\mathrm{C} / \mathrm{EBP} \alpha$ and PPAR $\gamma$ controls the transcriptional pathway of adipogenesis and insulin sensitivity. Mol Cell 3: $151-158$.

Yarwood SJ, Sale EM, Sale GJ, Houslay MD, Kilgour E, Anderson NG. 1999. Growth hormone-dependent differentiation of 3T3-F442A preadipocytes requires Janus kinase/signal transducer and activator of transcription but not mitogen-activated protein kinase or p70 S6 kinase signaling. J Biol Chem 274: 8662-8668.

Yeh WC, Cao Z, Classon M, McKnight SL. 1995. Cascade regulation of terminal adipocyte differentiation by three members of the C/EBP family of leucine zipper proteins. Genes Dev 9: 168-181.

Yu CY, Mayba O, Lee JV, Tran J, Harris C, Speed TP, Wang JC. 2010. Genome-wide analysis of glucocorticoid receptor binding regions in adipocytes reveal gene network involved in triglyceride homeostasis. PLoS One 5: e15188. 


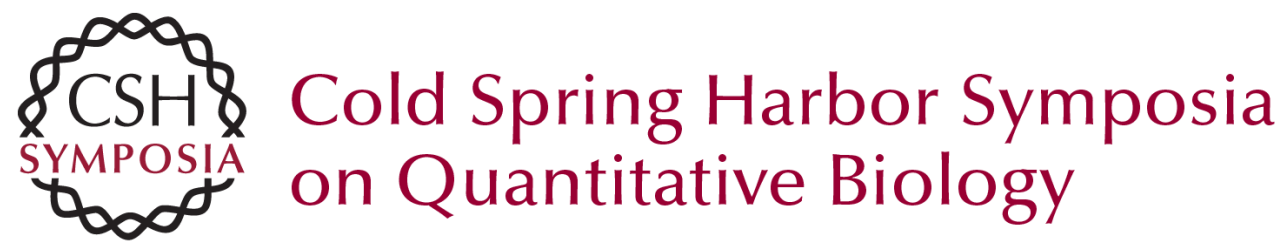

\section{Transcriptional Networks Controlling Adipocyte Differentiation}

R. Siersbæk and S. Mandrup

Cold Spring Harb Symp Quant Biol 2011 76: 247-255 originally published online September 6, 2011

Access the most recent version at doi:10.1101/sqb.2011.76.010512

References This article cites 85 articles, 39 of which can be accessed free at: http://symposium.cshlp.org/content/76/247.full.html\#ref-list-1

\section{License}

Email Alerting Receive free email alerts when new articles cite this article - sign up in Service the box at the top right corner of the article or click here. 